\title{
Analysis of Hedges in English Advertising from the Perspective of Cooperative Principle
}

\author{
Jing Yang \\ School of Humanities, Tianjin Polytechnic University, Tianjin, China \\ Email: 2487682064@qq.com
}

How to cite this paper: Yang, J. (2019) Analysis of Hedges in English Advertising from the Perspective of Cooperative Principle. Open Access Library Journal, 6: e5441. https://doi.org/10.4236/oalib.1105441

Received: May 5, 2019

Accepted: June 8, 2019

Published: June 11, 2019

Copyright $\odot 2019$ by author(s) and Open Access Library Inc.

This work is licensed under the Creative Commons Attribution International License (CC BY 4.0).

http://creativecommons.org/licenses/by/4.0/

\begin{abstract}
Hedge is a phenomenon of the fuzziness in language. It is also a particularly crucial communication strategy. This thesis analyzes hedges in English advertising on the basis of Cooperative Principle. The thesis promotes the further study of hedges from different perspectives. Advertisers are also able to adopt hedges in a better way for promoting their products and services. At the same time, it may help them to understand the strategies well. More importantly, it promotes the study of the advertising and cooperative principle.
\end{abstract}

\section{Subject Areas}

Education, Linguistics

\section{Keywords}

Hedges, English Advertising, The Cooperative Principle

\section{Introduction}

As the rapid development of society, advertising plays a more and more important role in our daily life, as well as the business world. Advertising language is informative, simple, accurate and persuasive [1]. In fact, advertising is a bridge between consumer and producer. Advertising attracts and persuades consumers to make purchases, because it can create strong desires to convince readers of advertisement to purchase the products. Thus, consumers can get more information about the products and services through advertising, and finally purchase some things that they need. Hence, studying the language of English advertising is of great importance.

As a common language phenomenon in our daily life, a successful advertising should possess the following qualities: believability, simplicity and readability 
[1]. Therefore, advertising language differs from other languages. While in the course of studying advertising language, plentiful usage of hedges could be noticed in English advertising. As an important member of vague language, hedges become the research goal of linguists. Hedges are an effective approach to expression and communication. In addition, it is a common phenomenon in human language [2].

Recently, a lot of studies of hedges have been completed from different aspects such as semantics, pragmatics, phonetics and so on. The study of hedges in English advertising is a field which has not been paid enough attention. Consequently, it is a valuable section to be explored. From the perspective of Cooperative Principle, this study aims at investigating the pragmatic functions of hedges in English advertisements so as to help advertisers create more effective advertisement and persuade consumers to be interested in the goods' information in the advertisements. In addition, the study aims at providing people with a comprehensive understanding of hedges in English advertisements.

There are some theoretical and practical significance of this research. Firstly, it helps us to comprehend the nature of hedges better, such as the linguistic features and pragmatic functions of hedges. Secondly, it also helps to make the better understanding of the hedges in English advertising properly for consumers, in order not to be cheated easily by some advertisements. Thirdly, it can help raise advertisement writers' consciousness to employ hedges reasonably and to achieve the suitable effect. Lastly, it throws some enlightenment on language teaching and helps students to learn how to use hedges appropriately to achieve their communicative objectives.

\section{Literature Review}

Hedges and advertising are the most important key words in this thesis, which lay a solid foundation for the further study of hedges in English advertising. This section focuses on the study of hedges at home and abroad.

\subsection{Studies on Hedges Abroad}

Vagueness is a common phenomenon in language use [2] [3], but it isn't valued at the beginning. With the rapid development of economy and technology, more and more scholars are focused on the fuzziness of language. At the beginning of the $20^{\text {th }}$ century, Peirce (1911) defines the vagueness: "A proposition is vague when there are possible states of things concerning which it is intrinsically uncertain whether, had they been contemplated by the speaker, he would have regarded them as excluded or allowed by the proposition" [4].

L. A. Zadeh was the first scholar to study hedges. In 1965, L. A. Zadeh introduced the theory of fuzzy set, and put forward the mathematical term like "membership function", "fuzzy set", and "grade of membership" into linguistics, which started a new era of the study of fuzziness in natural languages. In 1971, L. A. Zadeh explained linguistic hedges for the first time [3] [5]. In 1972, Zadeh di- 
vided English hedges into two types from the point of view of logic and semantics. In the case of hedges of the first category, typical hedges are slightly, more or less, highly, much, etc. The second type is words such as practically, regularly, essentially etc. [5].

Lakoff was regarded as the first person who put forward the term of hedges from the perspective of linguistic. He studied hedges from the point of view of semantics. In 1972, he indicated that the concept of natural languages were not simply, but were vague. In 1982, he introduced some expressions and phrases like "sort of", "to some extent", "kind of" are called hedges [2]. Lakoff noted that some hedges have deeper meaning which are beyond their surface meaning and aren't found in the dictionary.

Brown and Levinson (1987) studied the functions of hedges in academic and scientific discourse. They defined hedge as a means or an expression of avoiding disagreement [6]. According to them, hedge also was a means of negative politeness. Yule (1996) considered hedges as "cautions notes expressed about how an utterance is to be taken" [7]. Hyland (1998) focused on distributions, frequencies and the use of hedges in English scientific research writing [8]. Hedges become more and more popular for linguists.

JS Hoffman (2002) seen hedges as a separately layer of meaning potential contributing to construction of academic ideology [9]. Ideology construction can be built up cumulatively by hedges on discourse level instead of grammatical level. MD Stringer (2005) studied the hedges from the perspective of linguistic theory application and gained great achievements, which covers the field of lexicology, pragmatics, discourse analysis. He pointed out that fuzzy linguistics is a discipline formed by combination of fuzzy sets and modern linguistics [10]. JYT Mei (2007) analyzed hedges in discussion sections of English and Chinese. She found that in scientific researches, the use of hedges can make the statement of a proposition more precise and comprehensive, protect the author by reducing his responsibility, and show the author's respect for the readers [11].

\subsection{Studies on Hedges in China}

He Ziran (1985) was the famous researcher who started early to make research mainly on the vagueness from a pragmatic point of view and the interpersonal functions of hedges. In addition, professor He Ziran (1990) divided hedges into two types from the pragmatic perspective: the first type is called "Mitigate Hedges"; the second type is called "Variation Hedges" [12].

Wu Tieping (1999) was the first Chinese scholar who has introduced fuzzy theory into linguistic field of China. In 1999, he explained vagueness within the scope of semantic and philosophical. Later, he published almost 20 articles involving in fuzziness in Chinese. He also focused on the study of fuzzy words, such as words indicating time, size, color, etc. He agreed with the two types of hedges adopted by Zadeh. He also pointed out that hedges can be divided into two categorizations from another perspective. He assumed that the interpreta- 
tion of words was definition, which had extension, but sentences were ambiguous [13].

Dai Weidong and Cai Longquan (2002) analyzed hedges based on the cooperative principles and speech act theory [14]. They attached much importance to the study of fuzzy words. They found that hedges are used in different fields. Wu Song (2008) studied hedges in English advertising from a stylistic perspective [1]. He pointed out that advertisements become more attractive, persuasive and fuzzy by using hedges. Hedges distinguish the degree of truth of members in a class and their structural information.

After introducing the view of hedges made by many famous scholars, we are able to figure out that the focus of hedging study has begun from the functional aspect, later expanding to more field. Meanwhile, we can find that hedges are often used in communication either in written communication or verbal communication for the sake of mitigation, politeness, indirectness, etc. To sum up, all the approaches related with hedges divided into two types: semantics and pragmatics. In this thesis, the author will study hedges in English advertising from pragmatics perspective.

\section{Theoretical Basis}

This section will give an elaborate introduction of Grice's Cooperative Principle, which lay a foundation for the study of hedges in English advertising.

\subsection{The Definition and Categorization of Hedges}

Different scholars define hedges are different and various. Lakoff (1972) was considered the first person who discoveries the hedges and makes the definition: "hedges are words whose job is to make things fuzzier and less fuzzy" [2]. Zadeh (1972) divided hedges into simply hedges such as more or less, much, very and complex hedges like practically, technically, essentially [3] [5]. Brown and Levinson (1987) considered hedges as "a particle, word or phrase that modifies the degree of membership that it is particle true only in certain respect, or that is truer and complete than perhaps might be accepted" [6]. These definitions are mainly analyzed from semantics or logics, concentrating on logical features of expressions. Later on, scholars study the hedges from pragmatic aspect. In Oxford Dictionary (2005), hedges' definition is: “Any linguistic device by which a speaker avoids being compromised by a statement that turns out to be wrong, a request that is not acceptable and so on" [15]. In addition, there are differences between hedge and hedging. In fact, hedging could be considered as the use of hedges in different contexts.

In the past 30 years, scholars studied on the definition of hedges vary from different perspectives. Hence, the categorization of hedges are also various. We can study the categorization of hedges from the perspectives of syntactics, semantics and pragmatics that are the most typical. This thesis emphasizes on the categorization from the perspective of pragmatics. 
Prince et al. (1982) pointed out there are two types of hedges from the perspective of pragmatics [16] [17]. The first type is approximators which refer to the words can modify the true-value of proposition. Therefore, approximators are able to alter the original meaning of a sentence to certain degree and even cancel it. There are two sub-categories of approximators: adaptors and rounders. Adaptors refer to the kind of hedges that the proposition is almost right but the addresser doesn't feel sure enough. A sentence employs adaptors will be more appropriate to the real situation, for example: sort of, kind of, more or less, somewhat, really. Rounders are effective hedges that can convey a certain range to a sentence in order to let the listeners understand. An utterance employs rounders make the original accurate numbers fuzzy, for instance: perhaps, roughly, nearly, around, approximately.

The second type is shields which means don't need to change the original meaning of utterance. Shields are also divided into two sub-categorized: plausibility shields and attribution shields. The first type is used to point out the speakers' attitude or statement on some topics. This type of expressions includes I am afraid, as far as I can tell, I think, I believe etc. The second type refers to the speakers cite the third person's words rather than their own one though they want to convey meaning. It often conveys the ideas of others. This kind of words such as somebody says that, it is said that, according to, it seems etc.

\subsection{Cooperative Principle}

The English language philosopher Paul Grice (1975) first put forward the Cooperative Principle. He defined it as "Make your contribution such as it is required, at the stage at which it occurs, by the accepted purpose or direction of the talk exchange in which you are engaged" [18]. The cooperative principle describes how effective communication in conversation is achieved in common social situation, that is to say, how listeners and speakers must act cooperatively and mutually accept one another to be understood in a particular way. Grice raises that speakers and hearers share the cooperative principle; speakers try their best to let their expressions to be understood by hearers.

Grice proposed that Cooperative Principle can be divided into four maxims: [18]

1) The maxim of Quantity

a) make your contribution as informative as is required

b) do not make your contribution more informative than is required

2) The maxim of Quality

Try to make your contribution one that is true, specially:

a) do not say that for which you lack adequate evidence

b) do not say what you believe to be false

3) The maxim of Relevance

a) make your contribution relevant

4) The maxim of Manner 
Be specifically and perspicuous:
a) avoid obscurity
b) avoid ambiguity
c) be brief( avoid unnecessary prolixity)
d) be orderly

(Grice, 2002: 26-27)

To sum up, these maxims show what speakers and hearers have to do for the purpose of communicating with each other and they ought to express clearly, sincerely and understandable. The goal of these maxims is to make utterance clear. However, Grice (1975: 212) points out: “a participant can obviously fail to observe a maxim at the level of what is uttered without any intention of deceiving or misleading, but he really expects to help the listeners explain the additional meaning called conversational implicature" [18]. The process of accounting for conversational implicature is generated as "violating a maxim". Nevertheless "violating a maxim" can always make a successful communicating. Of course, "violation of the maxim" are often exists in English advertisement.

Grice's Cooperative Principle is employed in this thesis to explore how and why advertisers adopt hedges in English advertising so as to seek out the functions in the use of hedges in English advertising.

\section{The Realization of Hedges in English Advertising}

From section three, the author has introduced the Cooperative Principle and the four maxims are employed to describe what actually happens in the conversation. However, in fact, participants will violate maxims intentionally. Violation of the maxims often exists in English advertising as well.

\subsection{Violation of Quantity Maxim}

By observing the maxim of quantity, the advertisers should make their contribution as informative as is required. In fact, it is impossible for advertisers to satisfy all the requirements and describe all the details of products or services, so advertisers employ hedges in the advertisements.

Example 1: In consumer testing, nearly $100 \%$ of people tested felt that their skin was immediately and intensely quenched. (Benefit)

This is an advertisement for cosmetics. In this advertisement, advertisers applied hedge on maxim of quantity. If they do not use the rounder "nearly" and just claim " $100 \%$ of people", this accurate number sounds unreasonable. The customers will probably don't believe the information and the advertisement will not be persuasive. However, by adding the word "nearly" advertisers can make the advertisement more fuzzier. The customers will not doubt the advertisers even though the accurate information is not $100 \%$ because the rounder "nearly" represents the meaning of more than $100 \%$ or less than $100 \%$. By violating the maxim of quantity, the advertisers attract consumers' attention and promote their products. 
Example 2: Maybe she is born with it. Maybe it is Maybelline. (Maybelline)

This is an advertisement for cosmetics. In this advertisement, advertisers employed the rounder "maybe" in the advertisement to improve the flexibility of the expression, because the hedge "maybe" refers that something hasn't got clear boundary. In order to defend themselves, advertisers use "maybe" to leave enough space to make consumers believe their products. Even if it is not as good as what customers expect, the advertisers could avoid taking responsibility and should not be criticized by the consumers because it is an approximation. By violating the maxim of quantity, the advertisers escape taking responsibility.

Example 3: This does save you eighty or so pence. (Vichy cosmetics)

In this advertisement, it is obvious that the advertisers feel certain about the exact saving and consumers have reason to believe that advertisers provide the actual price. But in terms of the purpose of advertisement, the actual price is not the important message to convey. Advertisers put the rounder "or so" in it to improve the flexibility of this utterance. The customers will not blame advertisers even though the actual price is not less than eighty, because the hedge "or so" involves the meaning of more than eighty or less than eighty. The approximation shows as much information as is necessary. At the same time, advertisers could evade the responsibility for making uncertain claims. That is to say, advertisers use hedges and violate maxim of quantity to contribute the effect of ensuring their self-protection and benefits.

Example 4: Dastun saves about a gallon of gasoline. (Dastun)

This is an advertisement for automobile. In this advertisement, advertisers must know the exact save of gasoline, but it is unnecessary to give the exact message. The rounder "about" is well-used to ensure self-protection even if the car doesn't save a gallon of gasoline. If advertisers leave out the word "about" and just claim "a gallon of gasoline", consumers will show doubtfulness about the advertisement. The hedge "about" gives justification for the fluctuation. Advertisers adopt the hedge "about" to provide the information so as to convince customers to buy the car and avoid taking responsibility. They violate the maxim of quantity to persuade consumers to buy their products.

\subsection{Violation of Quality Maxim}

According to the maxim of quality, advertisers should say the truth and not say what they believe false or untrue. However advertisers usually adopt some hyperbolic and puffing expressions in the advertisements so as to trigger consumers' interests and deepen their impression. Then in order to protect themselves from being blame, advertisers often employ hedges to advertisements to avoid trouble.

Example 5: Few things come along that actually change the way you live and work. This is one of those things. (AT \& T)

This is an advertisement for the company called America Telephone Telegraph. In this advertisement, advertisers use the adaptor "actually". In reality, 
the word "actually" refers to "in effect" instead of "in fact". This is confused by customers who tend to regard it as "in fact" rather than "in effect", which makes them to believe the claim and to attract the customers' attention and avoid being accused of. Advertisers employ hedges and violate the maxim of quality to trigger customers' interest and avoid being criticized by consumers.

Example 6: Always the low price, always. (Wal-Mart)

This is an advertisement for supermarket. In this advertisement, advertisers provide the message that Wal-Mart always gives the low price and consumers should choose it for the sake of saving money. But the message is not absolutely true, because the adaptor "always" is too definitely. Thus advertisers adopt hedges and violate the maxim of quality to capture readers' attention and persuade them to buy products.

Example 7: Come with features you rarelysee. (Compaq)

This is an advertisement for computer. In this advertisement, if we eliminate the adaptor "rarely", customers can't get the peculiarities of the product. At the same time, the advertisement seems to convey the untruthful message that other computers rarely have these features. So advertisers want to draw the attention of readers. They violate the maxim of quality and use the hedge "rarely" to leave a great impression on customers and stimulate them to take action.

Example 8: The great feeling that comes with knowing you've really gotten your money is worth and more. (Buick)

This is an advertisement for automobile. In this advertisement, advertisers adopt the adaptor "really" to emphasize the money is worth by driving this kind of car. Meanwhile, the word also plays an important role of modifying the expressions. It captures customers' psychology and strengthens the persuasiveness of the products. Finally, advertisers use hedges and violate the maxim of quality to reach their aim to persuade consumers to buy the products.

\subsection{Violation of Relevance Maxim}

The maxim of relevance requires the contribution relevant to the core information being contained in advertisements. In reality, in some cases advertisers violate this maxim and make use of hedges to convey some special effects of advertisements.

Example 9: We never take pride in prejudice. (The Times)

At first glimpse, the advertisement seems has nothing to do with the newspapers. However, consumers may find the relevance after they interpret it in connection with the context. This advertisement encourages customers to make associations to Jane Austin's (1813) Pride and Prejudice, booting the equity and sincerity of the newspaper. Advertisers employ the adaptor "never" to emphasize their newspaper's quality and try to capture readers' interest and lead them to buy the newspaper. All in all, advertisers use hedges and violate the maxim of relevance to encourage readers to buy the advertised newspaper.

Example 10: Just do it. (Nike) 
As for customers, they may get the first impression that this advertisement is irrelevant to the products. However, advertisers use the adaptor "just" to arouse readers' attention. "Just do it" implies that people should achieve their goals bravely and not afraid to experience failure. They should have enough encourage to take action. This is related to the spirit of sports. Advertisers want consumers to feel this kind of spirit and to purchase their products. Apparently, this advertisement succeeds in strengthening the effect of advertising language for promoting their products by using the hedge "just" and violating the maxim of relevance.

Example 11: Friendship is built on trust, respect and occasionally the scotch. (Ballantine's 12 Years Old the Scotch)

This is an advertisement for Whisky. In this advertisement, it seems that there is not any relationship between friendship and Scotch. Advertisers skillfully employ the adaptor "occasionally" to associate the wine with the true essence of friendship. Consumers may find the relevance between the advertisement and the product after they understand the advertisement in context. They find that wine and friendship have something in common and the characteristics of the wine are trust, respect which has been revealed by the word "occasionally". If the word "occasionally" isn't added by the advertiser, consumers will find it impossible to believe the advertisement because it sounds absolute. "Friendship is built on trust, respect and wine" is not so persuasive. Thus, advertisers employ hedges to emphasize the effect of advertising language for persuading customers to buy the wine.

Example 12: The only sound you'll hear is praise. (Lexus)

This is an advertisement for automobile. From the literal meaning of this advertisement, it is difficult for consumers to associate the voice of praise with the sound of the car. But the intentional violation of the maxim of relevance has a special meaning: Driving the car is very good so that consumers cannot hear any noise from the car but replaced by the praise of people. Advertisers use the adaptor "only" to give consumers a deeper impression and inspire them to buy the product.

\subsection{Violation of Manner Maxim}

The maxim of manner requires the speakers try to express meaning specifically and perspicuous, avoiding obscurity and ambiguity. The advertising language is clear and short, but in order to make their products attract the customers, advertisers often violate the maxim of manner and use some hedges intentionally.

Example 13: Say goodbye to dry skin and hello to "total moisture". (Benefit facial cream)

When people read the advertisement, they may be confused and cannot grasp the detailed message about the products. There is an unclear and ambiguous expression: How much moisture the facial cream will bring? The adaptor "total" intensifies the attraction of the products to attract customers. The advertisement 
conveys the information is vague but triggers customers' interest and inspire their curiosity. They may want to look at it and to take action to but it.

Example 14: Clinique, only some women have it. (Clinique)

This is an advertisement for cosmetics. At the first glimpse, the readers may be confused by the advertisement and could not catch the message conveyed in it. How many women are worthy to have Clinique? There is no detail statement and customers cannot make clear the product immediately. It conveys to consumers the information is general and unclear. If they do not use the adaptor "some" and just claim "only women have it", this expression sounds absolute. The advertisers use the hedge "some" and violate the maxim of manner to capture consumers' attention and deliberately trigger them.

Example 15: Luxurious ride and expressive styling that make a very personal statement. (Chrysler Concorde)

This is an advertisement for automobile. In this advertisement, there is a general and unclear information about the advertised product and consumers may not grasp the theme. Nonetheless, the adaptor "very" is well-used to make the product more attractive. If the word "very" isn't added by the advertisers, customers will not know the unique features of the car. The word "very" is able to make the products more attractive so that advertisers realize their goal. Customers may take a look at them out of their consuming desire. By adopting the hedges "very" and violating the maxim of manner, advertisers make the information obscure deliberately so as to persuade customers to buy the products or services.

Example 16: The company made a sizable profit. (Unisys)

This is an advertisement for network technology company. In this advertisement, there is nothing details but a general and unclear expression. Consumers cannot make clear the advertised products: What benefits does it bring to us? So advertisers adopt the adaptor "sizable" to intensify the attraction of the products and inspire consumers to have a look. As for advertisers, it is helpful to achieve their aims that promote the products. The advertisers employ the hedge "sizable" and violate the maxim of manner to inspire consumers and promote their products.

To sum up, on the basis of Cooperative Principle, hedges work as an indispensable function in advertisements in order to help advertisers achieve their aims.

\section{Conclusions}

The analysis of hedges in English advertising is probably a complex topic in linguistics. People usually think that hedges in advertising lead to prompt the effectiveness of advertising and investigate fuzziness of natural language. Nowadays, advertisers make more efforts in advertising for promoting more products since the competitive markets. As the membership of fuzzy language, hedges have rich special functions. Therefore, advertisers widely employ them in English adver- 
tising and make the vague language an effective strategy in order to achieve attraction.

The thesis introduces the previous studies, definition and categorization of hedges. Then the thesis analyzes some examples by violating the Cooperative Principle to illustrate the functions of hedges as follows. Firstly, by violating the maxim of quantity and the maxim of quality, advertisers could avoid taking responsibility and should not be criticized by the consumers. That is to say, the usage of hedges ensures their self-protection and benefits. Secondly, by violating the maxim of relevance and the maxim of manner, advertisers reach their aims for attracting consumers' attention and stimulating them to take action. From these findings in the thesis, hedges can be used in English advertising and serve positive functions. However, as a kind of fuzzy expression, hedges can mislead or even deceive customers. Therefore, in the further study, how to use hedges appropriately in English advertising is a further topic that should be discussed.

\section{Acknowledgements}

I'd like to express my thanks to my supervisor, Professor Ma Daoshan who gives me some instructions and encouragement during the process of my thesis writing.

\section{Conflicts of Interest}

The author declares no conflicts of interest regarding the publication of this paper.

\section{References}

[1] Wu, S. (2008) English Advertising. Foreign Language Education and Research Press, Beijing.

[2] Lakoff, G. (1982) Hedges: A Study in Meaning Criteria and the Logic of Fuzzy Concept. Chicago Linguistic Society Paper, 8, 183-228.

[3] Zadeh, L. (1965) Introduction to the Theory of Fuzzy Sets. America Press, New York. https://doi.org/10.1016/S0019-9958(65)90241-X

[4] Peirce, C. (1911) Vagueness. In: Baldwin, J.M., Ed., Dictionary of Philosophy and Psychology, Macmillan, New York, 748.

[5] Zadeh, L. (1972) A Fuzzy-Set-Theoretic Interpretation of Linguistic Hedges. Journal of Cybernetics, 3, 4-34. https://doi.org/10.1080/01969727208542910

[6] Brown, P. and Levinson, S. (1987) Politeness: Some Universals in Language Usage. Cambridge University Press, Cambridge. https://doi.org/10.1017/CBO9780511813085

[7] Yule, G. (1996) Pragmatics. Oxford University Press, Oxford.

[8] Hyland, K. (1998) Hedging in Scientific Research Article. John Benjamins Publishing Company, Philadelphia. https://doi.org/10.1075/pbns.54

[9] Hoffman, J. (2002) Vague Language. Oxford University Press, Oxford.

[10] Stringer, M. (2005) The Discourse of Advertising. Routledge, London.

[11] Mei, J. (2007) Understatements and Hedges in English. John Benjamins, Amster- 
dam.

[12] He, Z. (2004) Contemporary Pragmatics. Foreign Language Education and Research Press, Beijing.

[13] Wu, T. (1999) Fuzzy Linguistics. Shanghai Foreign Language Education Press, Shanghai.

[14] Dai, W. and Cai, L. (2002) The Research about Hedges Accurate Information Possibility of Discourse. Foreign and Foreign Teaching, 8, 1-6.

[15] Matthews, P. (2005) Oxford Dictionary. Oxford University Press, Oxford.

[16] Prince, E. (1982) On Hedging in Physician-Physician Discourse. Ablex Publishing Corporation, Amsterdam.

[17] Gao, X. and Zhang, Q. (2002) The Classification and Application of Hedges. Journal of School of Foreign Language of Sichuan University, 5, 89-91.

[18] Grice, P. (1975) Logic and Conversation. Harvard University Press, Harvard. 